\title{
BMJ Open Effects of expanding outpatient benefit package on the rationality of medical service utilisation of patients with hypertension: a quasi-experimental trial in rural China
}

\author{
Ruibo He, ${ }^{\oplus 1}$ Yudong Miao, ${ }^{2}$ Liang Zhang, ${ }^{1}$ Jian Yang, ${ }^{3}$ Zhong Li, ${ }^{\oplus 1}$ Boyang Li
}

To cite: He R, Miao Y, Zhang L, et al. Effects of expanding outpatient benefit package on the rationality of medical service utilisation of patients with hypertension: a quasi-experimental trial in rural China. BMJ Open 2019;9:e025254. doi:10.1136/ bmjopen-2018-025254

- Prepublication history for this paper is available online. To view these files, please visit the journal online (http://dx.doi org/10.1136/bmjopen-2018025254).

Received 11 July 2018 Revised 8 February 2019 Accepted 5 March 2019

Check for updates

(C) Author(s) (or their employer(s)) 2019. Re-use permitted under CC BY-NC. No commercial re-use. See rights and permissions. Published by BMJ.

${ }^{1}$ School of Medicine and Health Management, Tongji Medical College, Huazhong University of Science and Technology, Wuhan, China

${ }^{2}$ Department of General Medicine, Henan Provincial People's Hospital, Zhengzhou, China

${ }^{3}$ Department of Medical Affairs, Guangdong General Hospital, Guangzhou, China

Correspondence to

Dr Boyang Li;

jimmylee1900@foxmail.com

\section{ABSTRACT}

Objective To estimate the effects of expanding outpatient benefit package on ameliorating the issues of overreliance on inpatient services and seeking higher level medical services in rural China.

Design A quasi-experimental design.

Setting and participants 1673 pairs of patients with hypertension were selected after using propensity score matching from Dangyang county (intervention group) and Zhijiang (control group) county, Hubei province.

Intervention The outpatient annual reimbursement capping line was expanding from $¥ 300$ to $¥ 600$, daily capping line from $¥ 10 / 12$ to $¥ 150$. The compensation scope and institution were also enlarged from January 2016.

Outcome measures The difference-in-differences model was used to estimate the effects on medical service type selection. $\chi^{2}$ test was used to verify the effects on medical institution selection. We also examined the effects on health outcomes through the length of stay and blood pressure changes.

Results The intervention was associated with 3.225 times $(p=0.001)$ increase in total visits. Outpatient visits increased by 3.3 times $(p=0.008)$, whereas the township level presented a maximum increase of 1.932 times $(p=0.001)$. The inpatient visits declined by 0.075 times $(p=0.000)$, whereas county-level inpatient visits reached a maximum decrease of 0.042 times $(p=0.033)$. Meanwhile, the township level exhibited a maximum proportion growth of $14.8 \%$ in outpatient $(p=0.000)$ and $13.3 \%$ in inpatient visits $(p=0.048)$. Outpatient visits at the county level dropped at $13.2 \%(p=0.000)$, whereas inpatients visits declined by $7.7 \%(p=0.040)$. The length of stay and blood pressure were decreased, respectively, compared with the control group.

Conclusion Improving outpatient benefit package alleviated patient dependence on inpatient services through motivating outpatient service utilisation, consolidated the primacy of township health centres and guided patients to return to primary medical institutions. The health insurance reform should 'take the long view' in the future, and more attention should be paid to the rationality of medical service utilisation.
Strengths and limitations of this study

- This study started from a new perspective of rationality to assess the guiding and optimising effects of health insurance on the medical service system within the county.

- To ensure reliability of the results, a propensity score matching method was used to eliminate heterogeneity, and the difference-in-differences model was applied to control time effects.

- This study collected no medical record information and cannot assess whether the services are overused or irrational.

- The degree of cost saving and enhancement in insurance fund usage efficiency remain unknown.

\section{INTRODUCTION}

The living standards of residents visibly improved with the development of socioeconomics, adjoining their attention and need for healthcare. On the other hand, the ageing trend and the prevalence of chronic diseases became more notable. ${ }^{1}$ To cope with such challenges, the Chinese government has launched a new round of healthcare reform supported by infusions of hefty public funding, which jumped from $¥ 481.6$ billion to $¥ 836.6$ billion. The reform nearly achieved the universal health insurance coverage and consolidated the infrastructure of primary healthcare facilities. ${ }^{2}$ However, the issue of 'too inaccessible and too expensive care' remain unresolved. ${ }^{3}$ In the context of autonomous medical service seeking, given the lack of effective guidance and restraint mechanisms for patients, the actual service utilisation generated based on preferences often mismatch the patient needs, ${ }^{4}$ causing serious consequences.

From the medical service-type perspective, an issue of the over-reliance on inpatient 
services exists. ${ }^{5}$ Comparing with hospitalisation (90\%), the proportion of outpatient reimbursement $(20 \%)$ is much lower, ${ }^{6}$ and specific medicines can only be reimbursed for use in inpatient services. Therefore, rural patients prefer inpatient services although their disease can be cured with outpatient visits. On the other hand, the doctors' income is still related to their service quantity, implying that they earn more and achieve more development space with increasing patients and services provided. In the case of 'moral hazard' and 'induced demand, ${ }^{78}$ these sides may collude with each other, thus aggravating the problem of over-reliance.

From the medical institution perspective, one issue involves seeking higher level medical services than what are actually needed. ${ }^{9}$ Although different levels of medical institutions own an explicit and relatively distinguished functional orientation, ${ }^{10}$ patients still distrust primary medical institutions because of negative news, unfamiliarity caused by little contact, and influence from other patients. As they can select their own medical institution autonomously, with the improvement of income and convenience of transportation, they are no longer limited to rely on primary services provided by village doctor and township health centres and reach out to county-level and outside-county hospitals.

Insufficient service utilisation poses another problem. The two latest National Health Service Surveys have shown that the 2-week prevalence rate has increased significantly, but the attendance rate has declined and is significantly lower than the prevalence rate. ${ }^{11}$ The situation in rural areas, where the economic level and medical resources are relatively regressive, is more pronounced; this situation may lead to further deterioration and impairment of health and higher medical costs, which are major causes of poverty due to illnesses. ${ }^{12}$

If the actual need of patients can be satisfied in a timely manner and in a reasonable sector, the entire medical service system shall be optimised, making service utilisation a hot spot for reform and research. Existing research can be summed up in two dimensions. From the internal perspective, studies mainly analysed the influencing factors of utilisation; these factors can be divided into different themes according to objects, such as gender, ${ }^{13}{ }^{14}$ age $^{15}$ and household registration, ${ }^{4} 16$ socioeconomic level, ${ }^{17}$ compensation methods, ${ }^{18-20}$ service types ${ }^{21-23}$ and so on. Most studies drew on Andersen's behavioural model ${ }^{24}$ and proposed recommendations based on related findings. From the external perspective, other studies mainly focused on the utilisation effects, including the subjects of equality, ${ }^{4}$ accessibility, ${ }^{25}$ efficiency ${ }^{26}$ and expenditure. ${ }^{27}$ Less attention was paid to the field of rationality.

Given that the universal health insurance coverage and compensation of insurance account for more than half of the hospitals' revenue, ${ }^{28}$ payment reform plays an increasingly important role. However, more attention is paid to the constraints and regulations on suppliers, and guidance for demanders' service utilisation is limited. The existing reforms related to outpatient benefit package exhibit inadequate stimulation (low annual capping line) to change patient preference or habits. ${ }^{29-31}$

The process of generating medical services can be summarised as follows: feeling out of sorts; self-judgment on whether to seek medical service; the choice of medical institution; the doctor's decision on providing the needed kind of services; patient's decision on whether to accept the service. The issues of equality, accessibility and rationality happen at the preceding stages. The first two items have been improved significantly with the deepening course of national healthcare reform. However, under the background of autonomous medical service seeking, the issue of rationality becomes prominent and affects the cost and efficiency of medical services. Therefore, assessing the effects of expanding outpatient benefit package on alleviating the issues of over-reliance on inpatient services, seeking higher level medical services and insufficient service utilisation enlightens the construction of a rational chronic disease service system in rural areas with relatively poor health resources and will also contribute to global health reform.

\section{METHODS}

\section{Study settings and intervention assignment}

Hubei Province in Central China features a population of 58.52 million. Rural areas account for $43.15 \%$ of the province. Per capita gross domestic product in Hubei ranked 13th among 32 provinces and municipalities in $2015 .{ }^{28}$ Dangyang (DY) is a county-level area in Yichang city, Hubei province. From 2011 to 2015, its average annual hospitalisation rate has increased by $4.9 \%$. This result was attributed to the growth of hospitalisation happened beyond the county-level medical institutions. The share of county-level hospitalisation declined from $65.0 \%$ to $49.9 \%$. The proportion of township health centres fluctuated around $30 \%$. Meanwhile, the growth of inpatients was significantly faster than that of outpatients at the same period. Stage 3 hypertension (according to Chinese guidelines for the management of hypertension, stage 3 refers to systolic blood pressure $(\mathrm{SBP}) \geq 180 \mathrm{~mm}$ $\mathrm{Hg}$ and diastolic blood pressure (DBP) $\geq 110 \mathrm{~mm} \mathrm{Hg}$ and is more serious than stage 2) was considered an example from where outpatient-inpatient ratio (OIR) was calculated. OIR indicates the extent of outpatient versus inpatient service utilisation. The figures reached 44.74, 41.20, $40.77,39.71$ and 32.58 and exhibited a downward trend, reflecting the patients' dependence on inpatient services.

To encourage patients to use outpatient services, to alleviate the reliance on inpatient services and use the geographic and economic advantages of primary medical institutions, thus to promote patients' rational service utilisation, the local health administration implemented a reform expanding the outpatient benefit package aimed at stage 3 patients with hypertension. This group was selected for the following reasons: hypertension is a typical chronic disease with a high incidence, ${ }^{32} 33$ which requires multiple utilisation of medical services. 
Hypertension is also the main cause of cardiovascular and cerebrovascular diseases. ${ }^{34}$ When hypertension reaches stage 3, patients often suffer from functional or organic damages of the heart, brain and kidneys; they bear longterm medical care and outlay. Nevertheless, hypertension remains a controllable disease,$^{35}$ and controlling the patients' blood pressure through drug intake and certain outpatient treatment can reduce or delay the occurrence of complications, thus makes the substitution effect of outpatient service on inpatient service possible. ${ }^{36}$

Before intervention, the outpatient daily reimbursement capping line was $¥ 10$ for village clinics and $¥ 12$ for township health centres. The annual capping line was $¥ 300$ for insured rural residents, and only basic treatment at township or village level institutions was covered in the compensation scope. The exceeding expenses occurring at the county or higher level are self-paid. The intervention contents include the following: expanding annual capping line to $¥ 600$, daily capping line to $¥ 150$ and covering all outpatient services at village/township/ county-level institutions. If the actual costs are less than $¥ 600$, the balance will be automatically cleared at the end of the year. After a half-year preparation, the project was implemented in January 2016.

\section{Study design and sample selection}

To evaluate the effects, November-December 2015 (before intervention) and January-February 2016 (after intervention) were compared. To achieve more reliable results, we selected Zhijiang (ZJ) county as the control group. ZJ is also a county-level area in Yichang city, and several of its key indicators lie close to those of DY (table 1). The daily reimbursement capping line is $¥ 10$ for village clinics and township health centres. The annual capping line is $¥ 300$, which is the same with that of DY. No change was observed during the intervention period. Meanwhile, no adjustment was made in the inpatient reimbursement policy of both groups. The average inpatient reimbursement ratio was about $50 \%$.

Considering the contiguous locations of the two counties (figure 1), the reform in DY may cause emulation in ZJ, leading to mixed effects. Therefore, the evaluation adopted the single-blind method: DY was unaware that the control group was ZJ, and ZJ was unaware that the

\begin{tabular}{|c|c|c|}
\hline Indicators & Dangyang & Zhijiang \\
\hline Location & $\begin{array}{l}\text { Contiguous to } \\
\text { Zhijiang }\end{array}$ & $\begin{array}{l}\text { Contiguous to } \\
\text { Dangyang }\end{array}$ \\
\hline Administrative districts & 10 towns & 9 towns \\
\hline Population(thousand) & 486 & 496 \\
\hline Ageing population rate (\%) & 18.7 & 15.2 \\
\hline Urbanisation rate (\%) & 50.0 & 54.0 \\
\hline $\begin{array}{l}\text { Per capita annual income } \\
\text { (urban/rural, yuan) }\end{array}$ & 27 433/16 928 & $23675 / 15285$ \\
\hline
\end{tabular}

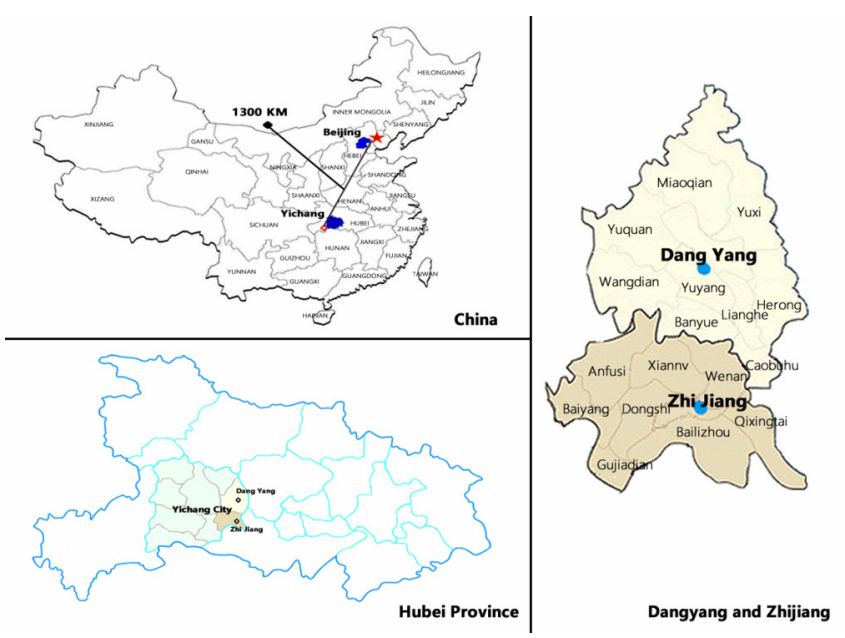

Figure 1 Location of the two counties in China and in Hubei province.

collected information will be used for comparative analysis. The medical service provision and utilisation were close to natural observations, avoiding the bias caused by intervention.

The inclusion criteria of participants comprised the following: (1) insured rural residents; (2) local permanent inhabitants (the definition of 'permanent' is referred to in the National Health Services Survey); (3) history of hypertension and diagnosis of stage three hypertension or its complications by township health centres and higher medical institutions; (4) ownership of reports of inspection results of electrocardiography and chest X-ray. The study excluded patients who died in 2015-2016 and were not permanent inhabitants. Based on the above criteria, we screened stage 3 patients with hypertension out of 2089 and 3053 individuals in DY and ZJ, respectively.

\section{Patient and public involvement}

The study was designed to assess the effects of expanding outpatient benefit package on improving rational health service utilisation based on a quasi-natural experiment trial. The intervention did not cast burden on patients. Patient's information was obtained from the local health insurance agencies and patient's electronic heath records, anonymised and deidentified before analysis. Therefore, patients were not involved in the recruitment or conduct of the study, and their information was unable to disseminate.

\section{Statistical analysis}

To avoid the confounding effects, a greedy matching procedure with callipers set at $0.1 \mathrm{SD}$ of the probit of the propensity score was used to create matched pairs. For each propensity score, we computed the standardised differences for sex, age, annual income, DBP and SBP in the matched sample. ${ }^{37}$

Basing on the matched subjects through propensity score matching method (PSM), our study used the fixed effect estimation method of difference in differences (DID) ${ }^{38}$ to testify the effects on the issue of over-reliance 
Table 2 Propensity score matching (PSM) results of control and intervention groups

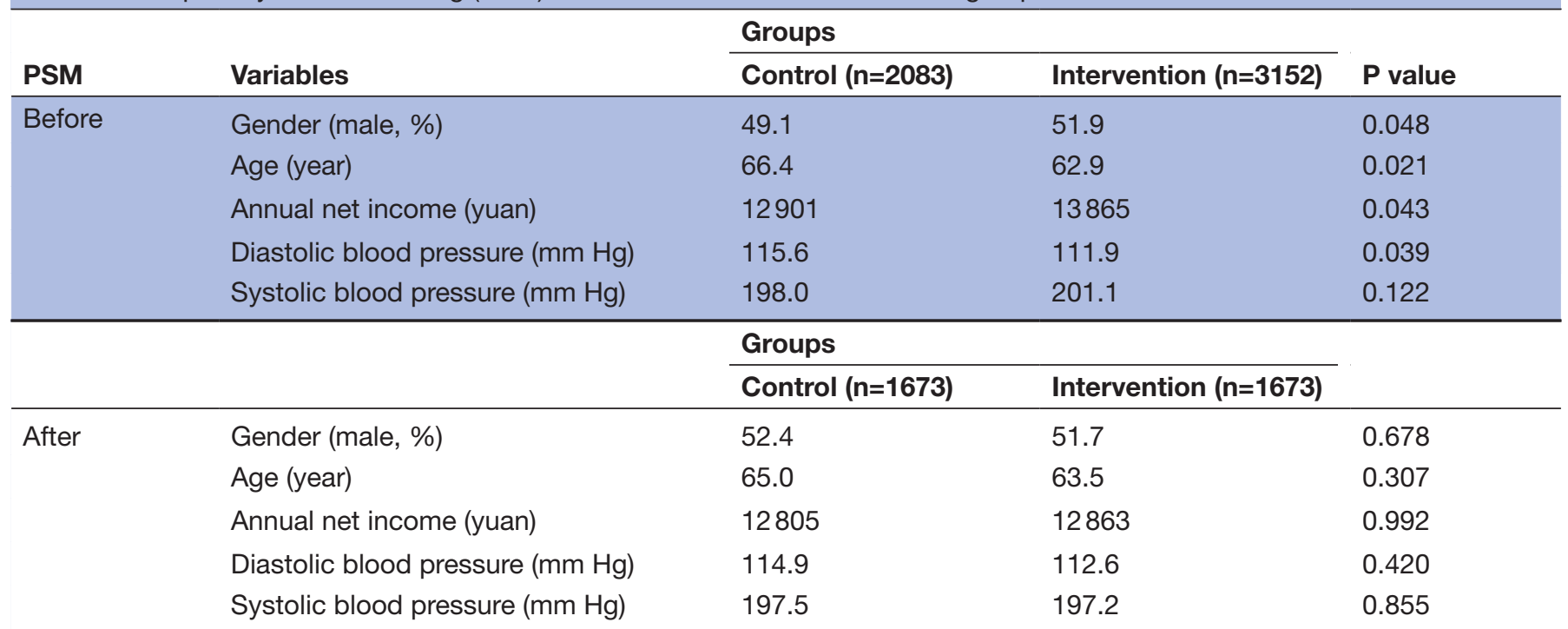

on inpatient services from the changes in outpatient and inpatient service utilisation.

$\chi^{2}$ analysis was conducted to examine the shifts in patients' medical institution selection before and after the intervention and testified whether expanding outpatient benefit package optimised the medical service utilisation structure. Any reform must consider health as the core starting point. Thus, we also analysed the changes in patient health outcomes and included the indicators of blood pressure and length of stay. $\mathrm{P}<0.05$ was considered as statistically significant, and STATA software (V.13) was used for all statistical analyses.

\section{RESULTS}

Before PSM, the proportion of men and annual net income in the intervention group was higher than that in the control group. The average age and average DBP in the intervention group were lower than the control group. No significant difference was observed in the average SBP between the two groups. After PSM, 1673 patients were present in each group, and gender, age, income and blood pressure were similar (table 2). The empirical results in the following paragraphs were all obtained from the 1673 matched type 3 patients with hypertension.

\section{Policy effects on the medical service-type selection}

Overall, the number of medical visits in the intervention group (DY) was 4.197 times per capita in 2015 and 4.243 times in the control group (ZJ), showing no statistical significance $(p>0.05)$. After the intervention, medical visits in DY rose to 7.427 times, indicating a growth of $76.9 \%$, whereas that of ZJ reached 4.248 times, presenting a statistically significant difference $(p<0.05)$. DID results showed that the net effect of the policy has increased the annual visits per capita of the intervention group (DY) by 3.225 times $(\mathrm{p}<0.05)$.
In the outpatient service aspect, no significant differences were observed in the visit number between DY and ZJ at baseline. Relative to ZJ, the intervention led to a significant increase at the integrated (4.072-7.353, growth of $80.58 \%)$, village $(0.721-1.051$, growth of $45.77 \%)$, township (1.881-3.925, growth of $108.67 \%$ ) and county level (1.299-2.123, growth of $63.43 \%)$. No statistical difference was observed beyond the county level. DID results indicated that policy net effects had augmented by 3.3 times at the integrated level, 0.249 times in the village clinics, 1.085 times in county hospitals and 1.932 times in the township health centres.

In the inpatient service aspect, the 0.125 times of visit per capita rate in DY was higher than that in ZJ $(0.063$ times) $(p<0.05)$. These figures observed in DY were also higher than those of ZJ at the township, county and beyond county level at baseline. After the intervention, the visit number declined to 0.074 times in DY, and no significant difference was observed compared with that in ZJ (0.087 times). At the township level, no significant difference was observed between the two groups, and the visit number in DY was lower than that of $\mathrm{ZJ}$ at the county and beyond county level $(p<0.05)$. The net effects had caused a decline of 0.075 times at the integral level, 0.042 times at the county level, 0.015 times beyond the county level and no significant change at the township level (table 3).

\section{Policy effects on medical institution selection}

The intervention led to outstanding changes in the flow of patients among institutions (table 4). The shift in outpatient distribution in DY resulted in the following. After the intervention, the proportion of village clinic visits dropped by $1.4 \%\left(\mathrm{x}^{2}=6.188, \mathrm{p}=0.013\right)$; patients were more inclined to township health centres, leading to an amplification of $14.8 \%\left(\mathrm{x}^{2}=389.506, \mathrm{p}=0.000\right)$. The proportion of county hospital visits declined most significantly at a 
Table 3 Results of difference-in-differences analysis on medical service-type selection ( $n=1673)$

2015 (Baseline)

\begin{tabular}{|c|c|c|c|c|c|c|c|}
\hline \multirow[b]{2}{*}{ Outcome variable } & & & \multirow[b]{2}{*}{ Diff-in-diff } \\
\hline & Control & Intervention & DIFF & Control & Intervention & DIFF & \\
\hline$P$ value & & & 0.862 & & & 0.003 & 0.001 \\
\hline Outpatient & 4.180 & 4.072 & -0.108 & 4.161 & 7.353 & $3.192^{\star \star}$ & $3.3^{\star *}$ \\
\hline$P$ value & & & 0.115 & & & 0.041 & 0.008 \\
\hline Village & 0.665 & 0.721 & 0.066 & 0.736 & 1.051 & $0.315^{\star *}$ & $0.249^{* *}$ \\
\hline Township & 1.810 & 1.881 & 0.071 & 1.922 & 3.925 & $2.003^{\star \star}$ & $1.932^{\star \star}$ \\
\hline$P$ value & & & 0.504 & & & 0.009 & 0.001 \\
\hline County & 1.588 & 1.299 & -0.289 & 1.327 & 2.123 & $0.796^{\star \star}$ & $1.085^{\star \star}$ \\
\hline$P$ value & & & 0.145 & & & 0.035 & 0.028 \\
\hline$P$ value & & & 0.000 & & & 0.095 & 0.000 \\
\hline Township & 0.022 & 0.042 & $0.02^{\star \star \star}$ & 0.028 & 0.03 & 0.002 & -0.018 \\
\hline$P$ value & & & 0.000 & & & 0.454 & 0.271 \\
\hline County & 0.034 & 0.065 & $0.031^{\star \star}$ & 0.047 & 0.036 & $-0.011^{\star *}$ & $-0.042^{\star \star}$ \\
\hline$P$ value & & & 0.001 & & & 0.042 & 0.033 \\
\hline Beyond county & 0.007 & 0.018 & $0.011^{\star \star}$ & 0.012 & 0.008 & $-0.004^{\star *}$ & $-0.015^{\star \star}$ \\
\hline$P$ value & & & 0.002 & & & 0.019 & 0.001 \\
\hline
\end{tabular}

${ }^{*} \mathrm{p}<0.10 ;{ }^{* \star} \mathrm{p}<0.05 ;{ }^{* \star \star} \mathrm{p}<0.001$.

value of $13.2 \% \quad\left(x^{2}=426.264, p=0.000\right)$. No significant change was observed in the occupation ratio of hospital visits beyond the county level $\left(\mathrm{x}^{2}=0.276, \mathrm{p}=0.599\right)$.

The shift in inpatient distribution resulted in the following. The proportion of hospitalisation in the township health centres increased from $33.3 \%$ to $44.6 \%$, with a growth of $11.3 \%\left(x^{2}=3.916, p=0.048\right)$. The county hospital was the patients' primary choice before and after the intervention but with no significant change in proportion $\left(\mathrm{x}^{2}=0.336, \mathrm{p}=0.562\right)$. The number of visits in hospitals beyond the county level decreased from $14.9 \%$ to $7.2 \%$, indicating a decrease of $7.7 \%\left(\mathrm{x}^{2}=4.225, \mathrm{p}=0.04\right)$.

\section{Policy effects on health outcomes}

As shown in table 5, no significant differences were observed in the DBP and SBP between DY and ZJ. The length of stay in DY was 0.49 day longer than that of
ZJ $(p<0.05)$ at baseline. After the intervention, DBP in DY experienced a slight reduction, and the DID results indicated that the policy net effects yielded a low DBP of $2.9 \mathrm{~mm} \mathrm{Hg}(\mathrm{p}<0.05)$. The SBP insignificantly declined to $7.9 \mathrm{~mm} \mathrm{Hg}(\mathrm{p}=0.508)$. The length of stay in DY decreased to 0.68 day and showed no significant difference compared with that of ZJ. DID results indicated that policy net effects had reduced to 0.45 day $(p<0.05)$.

\section{DISCUSSION}

Outpatient service is the patients' first contact point into the medical care system under shortage of fixed family doctor. Quality and timely outpatient service is the precondition for doctors to understand patients' real-time information, apply targeted treatment measures and manage

\begin{tabular}{|c|c|c|c|c|c|}
\hline Time (service type) & Village clinic & $\begin{array}{l}\text { Township health } \\
\text { centre }\end{array}$ & County hospital & Tertiary hospital & $P$ value \\
\hline 2016 (outpatient) & 2005 (16.3) & 7504 (61.0) & $2300(18.7)$ & $492(4.0)$ & \\
\hline 2015 (inpatient) & - & $70(33.3)$ & $108(51.8)$ & 31 (14.9) & 0.042 \\
\hline
\end{tabular}


Table 5 Results of difference-in-differences analysis on health outcomes $(n=1673)$

\begin{tabular}{|c|c|c|c|c|c|c|c|}
\hline \multirow[b]{2}{*}{ Outcome variable } & \multicolumn{3}{|c|}{2015 (Baseline) } & \multicolumn{3}{|c|}{2016 (Follow-up) } & \multirow[b]{2}{*}{ DIFF-IN-DIFF } \\
\hline & Control & Intervention & DIFF & Control & Intervention & DIFF & \\
\hline Diastolic blood pressure & 114.9 & 112.6 & -2.3 & 114.6 & 109.4 & $-5.2^{\star \star}$ & $-2.9^{\star \star}$ \\
\hline Systolic blood pressure & 197.5 & 197.2 & 0.3 & 203.6 & 196.0 & $-7.6^{\star}$ & -7.9 \\
\hline$P$ value & & & 0.420 & & & 0.095 & 0.508 \\
\hline$P$ value & & & 0.043 & & & 0.115 & 0.011 \\
\hline
\end{tabular}

${ }^{*} p<0.10 ;{ }^{* *} p<0.05 ;{ }^{* *} p<0.001$.

health. ${ }^{39}$ When insufficient outpatient service utilisation occurs, rural type 3 patients with hypertension, especially those lacking basic knowledge of prevention and control, are in the 'vacuum disease management' state. This situation case may cause serious complications and induce the issues of irrational service utilisation. As the administrator of the local health department said, 'some patients' medical service utilisation is in a model of 'either not seeing a doctor or seeing a doctor until the disease become more severe', provision of outpatient services is the key to improve the health status of type three hypertension patients.'

The intervention that expanded outpatient benefit package has played a remarkable role in guiding patients to use outpatient services. The DY outpatient visits raised to 7.35 times per capita, presenting an increase of $81 \%$. According to the results, township health centres are the main providers of outpatient services, followed by county hospitals and village clinics and tertiary hospitals outside the county. These levels can be attributed to the geographical convenience and economic accessibility of township health centres. At the same time, township health centres present remarkable advantages over village clinics in terms of equipment, capability and medicine supply, making them better at meeting patient needs. The reform further consolidated the primacy of the outpatient service provision by township health centres. The proportion increased from $41.6 \%$ to $61.0 \%$, which was contributed by the decrease in village clinics $(-1.4 \%)$ and county hospitals $(-13.2 \%)$.

Notably, the number of inpatient visits to tertiary hospitals outside the county declined by 0.015 times, revealing a drop of $83.3 \%$. County hospitals followed, with a decreased of 0.042 times $(64.6 \%)$. The township health centres exhibited no significant change, and their proportion raised by $11.3 \%$. These results may have originated from the multiple use of township health centre's outpatient services, where patients had established close ties with doctors and enhanced trust in institutions, playing a guiding role when selecting inpatient institution. On the other hand, the choice is also related to the characteristics hypertension. Patients can effectively control the development of blood pressure and complications by strengthening self-management and outpatient services during the stable period. The number of hospitalisation visits and the proportion of tertiary hospitals outside the county both showed a downward trend, indicating that patient needs can be satisfied within the county level. However, once patients enter the onset period, the advantages of inpatient services and high-level medical institution will appear. Under the existing health insurance policy, the reimbursement ratio for inpatient services still remains higher than that for outpatient services, and such condition will promote patients to select hospitalisation to a certain extent.

In Chinese rural areas, the problem of medical service underutilisation in patients with chronic disease remains an important factor affecting long-term health status. Although the intervention reduced the number of hospitalisations, the policy net effects showed that the total visit number increased by 3.225 times, showing a growth of $76.8 \%$. Analysis of health outcomes indicated that the average DBP and SBP decreased by 2.9 and $7.9 \mathrm{~mm} \mathrm{Hg}$, respectively. This result suggests that the intervention successfully enhanced outpatient service utilisation and resulted in multiple 'contacts' with institutions, thus improving health outcomes. On the other hand, the decline in inpatient visits at higher level institutions effectively reduced the average length of stay.

Based on empirical results, we can presume the following: (1) outpatient service can play a better control-and-management role in the stable stage of hypertension, thus curbing the unreasonable need for hospitalisation; (2) expanding the outpatient benefit package ameliorated medical service utilisation structure within the county. The adjustment of a reimbursement strategy can affect the patients' medical service-seeking behaviour, thus improving the irrationality caused by autonomous medical service seeking; and (3) the patients' demand elasticity of hospitalisation services and county-level institutions services is low and will always occur as part of the related behaviour. The health department should further reinforce the construction of village clinics and township health centres, improve their service capabilities and strengthen policy promotion. The insurance department can further expand the scope and intensity of reform and strictly control the indication of admission during the 
review process, thus suppressing the unreasonable admission from the supplier and demander sides.

\section{Limitations}

In addition to the indicators of gender, age, income and health status in the PSM, other factors, such as stress, education and distance from medical institutions, may affect service utilisation. We presume that these factors are similar and will cause no major influence on the results as socioeconomic and health resources of the two counties resemble each other, and the intervention target is mostly elderly people. At the same time, this research collected no medical record information and cannot assess whether the service is overused or irrational. Instead, we analysed the effects of intervention on the rationality from a system perspective. Although we have confirmed the effects of reducing the issue of over-reliance and optimising the utilisation structure, the degree of cost saving and the degree of enhancement in insurance fund usage efficiency remain unknown. Future works should focus on the cost and efficiency to determine whether this reform is proper and sustainable. Furthermore, due to the differences in the distribution and balance of the medical insurance funds in each county, it is not necessary to be completely consistent with the sample point. But tilting toward outpatient compensation can be served as exploration direction for other counties.

\section{CONCLUSION}

The reform of expanding outpatient benefit package shifted reimbursement policy priority from being heavily concentrated on inpatient expenses to balanced coverage of outpatient and inpatient expenses, increased outpatient service utilisation and reduced over-reliance on hospitalisation effectively. The consolidation of the primacy of chronic diseases treatment in township health centres and visit number growth in village clinics indicated that patients gradually return to primary medical institutions. To a certain extent, the reform optimised the structure and efficiency of medical service utilisation and reversed the 'Matthew effect' of the insurance funds usage. ${ }^{40}$ However, despite confirming the guiding role of payment on patients, ensuring and promoting the health of residents are the priorities of any reform. We should 'take the long view' in the future, and more attention should be paid to the rationality of health service utilisation to finally reach this goal: 'If patients' needs can be met by outpatient services, then no hospitalisation will be required; if residents' needs can be met by prevention and management, then no outpatient services will be required; patients show willingness to select primary medical institutions to ensure that their needs can be met satisfactorily'.

Acknowledgements The authors would like to thank the staff of health management department and health insurance department of DY county and ZJ county for their support on the research. They also want to thank the associate editor and reviewers for their careful review and insightful comments which have led to significant improvement of the manuscript.

Contributors RH analysed data and drafted the manuscript. YM collected data and modified the manuscript. LZ, JY and ZL checked the language and modified the manuscript. BL negotiated with local health department and gave guidance on study design. All authors read and approved the final manuscript.

Funding National Natural Science Foundation of China (NSFC), Contract no. 71673099/G0308.

\section{Competing interests None declared.}

Patient consent for publication Not required.

Ethics approval The study protocol conformed to the guidelines of the Ethics Committee of the Tongji Medical College of Huazhong University of Science and Technology (IORG no: IORG0003571).

Provenance and peer review Not commissioned; externally peer reviewed.

Data sharing statement Data will not be shared because the authors promised the related department that the information was only used for research, and it would not be disclosed.

Open access This is an open access article distributed in accordance with the Creative Commons Attribution Non Commercial (CC BY-NC 4.0) license, which permits others to distribute, remix, adapt, build upon this work non-commercially, and license their derivative works on different terms, provided the original work is properly cited, appropriate credit is given, any changes made indicated, and the use is non-commercial. See: http://creativecommons.org/licenses/by-nc/4.0/.

\section{REFERENCES}

1. He R, Ye T, Wang J, et al. Medical service quality, efficiency and cost control effectiveness of upgraded case payment in Rural China: a retrospective study. Int J Environ Res Public Health 2018;15:2839.

2. Yip W, Hsiao W. Harnessing the privatisation of China's fragmented health-care delivery. Lancet 2014;384:805-18.

3. Pan J, Tian S, Zhou Q, et al. Benefit distribution of social health insurance: evidence from china's urban resident basic medical insurance. Health Policy Plan 2016;31:853-9.

4. Liang Y, Guo M. Utilization of health services and health-related quality of life research of rural-to-urban migrants in China: a crosssectional analysis. Soc Indic Res 2015;120:277-95.

5. Siu AL, Sonnenberg FA, Manning WG, et al. Inappropriate use of hospitals in a randomized trial of health insurance plans. $N$ Engl J Med 1986;315:1259-66.

6. Wang C, Zhu S, Chen XY, et al. Analysis of disease of the excessive demand patients covered by the new rural cooperative medical system in a County, Hubei. Medicine and Society 2013;26:18-20.

7. Baicker K, Mullainathan S, Schwartzstein J. Behavioral Hazard in Health Insurance. Q J Econ 2015;130:1623-67.

8. Shain M, ROEMER MI. Hospital costs relate to the supply of beds. Mod Hosp 1959;92:71-3.

9. Xf L, Zhang S. Causes of Overtreatment and Its Countermeasures. Medicine and Society 2013;26:60-2.

10. Yip WC, Wang H, Liu Y. Determinants of patient choice of medical provider: a case study in rural China. Health Policy Plan 1998;13:311-22.

11. Jin YZ, Zhu WM, Zhang YG, et al. Impact of Healthcare System Development on healthcare seeking behavior among patients in China. Chinese Health Economics 2017;36:67-70.

12. Wang HP, Wang ZS, Pc M. Situation analysis and thinking about poverty caused by illnesses in rural areas-Based on research data of 1214 families whose poverty is caused by illnesses in 9 Provinces in West China. Economist 2016;10:71-81.

13. Bertakis KD, Azari R, Helms LJ, et al. Gender differences in the utilization of health care services. J Fam Pract 2000;49:147-52.

14. Ahmed S, Creanga AA, Gillespie DG, et al. Economic status, education and empowerment: implications for maternal health service utilization in developing countries. PLoS One 2010;5:e11190.

15. Li J, Feng XL. Health care-seeking behaviours and health expenditures in adults aged 45 years and older in China, 2011-2013. Trop Med Int Health 2017;22:638-54.

16. Liu M, Zhang Q, Lu M, et al. Rural and urban disparity in health services utilization in China. Med Care 2007;45:767-74.

17. Dunlop S, Coyte PC, Mclsaac W. Socio-economic status and the utilisation of physicians' services: results from the Canadian National Population Health Survey. Soc Sci Med 2000;51:123-33. 
18. Dong $\mathrm{H}$. Health financing policies: patient care-seeking behavior in rural China. Int J Technol Assess Health Care 2003;19:526-32.

19. Jowett M, Deolalikar A, Martinsson P. Health insurance and treatment seeking behaviour: evidence from a low-income country. Health Econ 2004;13:845-57.

20. Ali MM, Teich J, Woodward A, et al. The implications of the affordable care act for behavioral health services utilization. Adm Policy Ment Health 2016;43:11-22.

21. Wu D, Lam TP, Lam KF, et al. Public views towards community health and hospital-based outpatient services and their utilisation in Zhejiang, China: a mixed methods study. BMJ Open 2017;7:e017611.

22. Mendoza-Sassi R, Béria JU, Barros AJ. Outpatient health service utilization and associated factors: a population-based study. Rev Saude Publica 2003;37:372-8.

23. Zhang P, Zhao L, Liang J, et al. Societal determination of usefulness and utilization wishes of community health services: a population-based survey in Wuhan city, China. Health Policy Plan 2015;30:1243-50.

24. Andersen RM. Revisiting the behavioral model and access to medical care: does it matter? J Health Soc Behav 1995;36:1-10.

25. Meng Q, Xu L, Zhang Y, et al. Trends in access to health services and financial protection in China between 2003 and 2011: a crosssectional study. Lancet 2012;379:805-14.

26. Sun J, Luo H. Evaluation on equality and efficiency of health resources allocation and health services utilization in China. Int $J$ Equity Health 2017;16:127.

27. Martin AB, Hartman M, Washington B, et al. National Health Spending: faster growth in 2015 as coverage expands and utilization increases. Health Aff 2017;36:166-76.

28. He R, Miao Y, Ye T, et al. The effects of global budget on cost contro and readmission in rural China: a difference-in-difference analysis. $J$ Med Econ 2017;20:903-10.

29. Gotsadze G, Tang W, Shengelia N, et al. Determinants analysis of outpatient service utilisation in Georgia: can the approach help inform benefit package design? Health Res Policy Syst 2017;15:36
30. Hao Y, Wu Q, Zhang Z, et al. The impact of different benefit packages of Medical Financial Assistance Scheme on health service utilization of poor population in rural China. BMC Health Serv Res 2010;10:1-13.

31. Tang SN, Jian WY, Yip WC, et al. [Impact of primary care oriented outpatient benefit package design in new rural cooperative medical system on hypertension outpatient services utilization]. Beijing Da Xue Xue Bao Yi Xue Ban 2014;46:445-9.

32. He J. Comparison of secular trends in prevalence of hypertension in the People's Republic of China (PRC) and the United States of America (USA). Am J Hypertens 1996;9:74A.

33. Wu X, Duan X, Gu D, et al. Prevalence of hypertension and its trends in Chinese populations. Int J Cardiol 1995;52:39-44.

34. Whitworth JA. World Health Organization, International Society of Hypertension Writing Group. 2003 World Health Organization (WHO)/International Society of Hypertension (ISH) statement on management of hypertension. J Hypertens 2003;21:1983-92.

35. Wolf-Maier K, Cooper RS, Kramer H, et al. Hypertension treatment and control in five European countries, Canada, and the United States. Hypertension 2004;43:10-17.

36. Jian WY, Fang $\mathrm{H}$. [An empirical analysis on the substitution effect of outpatient services on inpatient services]. Beijing Da Xue Xue Bao Yi Xue Ban 2015;47:459-63.

37. Miao Y, Gu J, Zhang L, et al. Improving the performance of social health insurance system through increasing outpatient expenditure reimbursement ratio: a quasi-experimental evaluation study from rural China. Int J Equity Health 2018;17:89.

38. Dimick JB, Ryan AM. Methods for evaluating changes in health care policy: the difference-in-differences approach. JAMA 2014;312:2401-2.

39. Ferschl MB, Tung A, Sweitzer B, et al. Preoperative clinic visits reduce operating room cancellations and delays. Anesthesiology 2005;103:855-9.

40. Zhang $\mathrm{RH}, \mathrm{Li} \mathrm{L}$. Analysis of structure and competition status of Health Service Market in Chengdu. Chinese Health Economics 2012;31:67-9. 